\title{
The Main Impacts of Infrastructure Works on Public Roads
}

\author{
Eduardo A. N. e Santos ${ }^{1}$, Clézio T. de S. Dutra ${ }^{2}$, Christine K. Chinelli ${ }^{1}$, Ahmed W. A. Hammad ${ }^{3}$, \\ Assed N. Haddad ${ }^{4}(\mathbb{D})$ and Carlos A. P. Soares ${ }^{1, * \mathbb{D}}$ \\ 1 Pós-Graduação em Engenharia Civil, Universidade Federal Fluminense, Niterói 24210-240, Brazil; \\ almeidaeduardo@id.uff.br (E.A.N.e.S.); cchinelli@id.uff.br (C.K.C.) \\ 2 Departamento de Engenharia Civil, Centro Federal de Educação Tecnológica, Rio de Janeiro 20271-110, Brazil; \\ clezio.dutra@cefet-rj.br \\ 3 Faculty of Built Environment, University of New South Wales, Sydney 2052, Australia; \\ a.hammad@unsw.edu.au \\ 4 Departamento de Construção Civil, Universidade Federal do Rio de Janeiro, Rio de Janeiro 21941-909, Brazil; \\ assed@poli.ufrj.br \\ * Correspondence: capsoares@id.uff.br; Tel.: +55-21-2629-5410
}

check for updates

Citation: Santos, E.A.N.e.; Dutra, C.T.d.S.; Chinelli, C.K.; Hammad, A.W.A.; Haddad, A.N.; Soares, C.A.P. The Main Impacts of Infrastructure Works on Public Roads. Infrastructures 2021, 6, 118. https://doi.org/ $10.3390 /$ infrastructures6090118

Academic Editor: Giuseppe Cantisani

Received: 30 June 2021

Accepted: 20 August 2021

Published: 24 August 2021

Publisher's Note: MDPI stays neutral with regard to jurisdictional claims in published maps and institutional affiliations.

\begin{abstract}
Infrastructure implementation and renovation in cities require work on public roads that impact the daily lives of road users and local population and commerce. Although the study of the impacts of infrastructure works in the researched literature has received various approaches, there is still a shortage of studies that identify the impacts of the implementation of infrastructure on public roads and the importance of each one. This study collaborates with this theme by researching the main impacts caused by infrastructure works on public roads based on extensive and detailed bibliographic research and based on a survey carried out toward residents of the areas impacted by these works, road users, and Brazilian professionals with experience in the concerned field. The results showed that fourteen impacts identified in the literature were considered important by survey respondents, of which seven were considered the most important.
\end{abstract}

Keywords: urban infrastructure; infrastructure services; infrastructure networks; infrastructure works; impacts; roads

\section{Introduction}

Urban infrastructure works have aroused the interest of researchers due to the increased demand for infrastructure services and its potential to produce social, economic, and environmental impacts. The increased demand for infrastructure services is directly related to factors such as the accelerated growth of cities [1-5] and the effects of climate change, such as flash floods [6].

The population growth experienced by most cities around the world has caused, in many cases, disorderly expansion, especially in underdeveloped and developing countries. In Brazil and other Latin American countries, land uses established by government plans and actions coexist, and informal urban conditions, such as slums and suburbs $[7,8]$, lack infrastructure services. In addition, population growth associated with the growing demand for quality of life has generated the need for improvements in infrastructure networks in cities [9,10]. More recently, the COVID-19 pandemic has also caused an increase in demand for infrastructure services, especially those related to online activities. This context has caused the daily installation and daily maintenance of infrastructure networks [11-13].

In the researched literature, the study of the impacts of infrastructure works has received several approaches. Some works address impacts related to specific works, such as the subway [4], to specific impacts, such as noise pollution [14,15], or focus on dimensions of sustainability [16-18]. On the other hand, more comprehensive works address more than one type of impact and construction [4,11,19-22]. 
After carrying out extensive and detailed bibliographic research, we did not find studies that aimed to identify the impacts of the implementation of infrastructure on public roads. What we found were impacts mentioned in broader contexts, such as in studies on the impacts of civil construction and in studies on the impacts of road works on the wellbeing of the population. In this context, this work contributes to the theme by identifying the main impacts from a reflective and interpretive reading of the articles selected in the bibliographic research. We also did not find works that identified the importance of these impacts. It is important to emphasize that the magnitude of the impact depends on the perception of those who are subjected to it. In this sense, this work innovates by prioritizing the impacts from the point of view of the residents of areas affected by these works, the road users, and the Brazilian professionals with experience in the concerned field.

The construction and reform of infrastructure have been important strategies used in improving the performance of the city's services, which has resulted in more frequent infrastructure works on public roads. By studying the impacts caused by these works, this research study provides companies, public bodies, managers, professionals, and legislators with information and conclusions that help to reduce these impacts. This paper is structured as follows: Section 2 presents a literature review, mainly addressing the impacts identified in the bibliographic research. Section 3 presents the procedures used in carrying out the bibliographic research, identifies the main impacts, surveys expert opinions, and provides data analysis. Section 4 presents and discusses the research results. Conclusions are provided in Section 5.

\section{Literature Review}

Through literature review, we identified the following impacts caused by infrastructure works on public roads: partial or total interdiction of vehicle traffic; interruptions and changes in local pedestrian traffic; reduction in public space used by the population; damage to the pavement; damage to the local economy; reduced tax collection; additional cleaning expenses; damage to preexisting networks, noise pollution; atmospheric pollution; the low energy efficiency of the operation; change in the local landscape, damage to the ecosystem present in the subsoil; and risks to the safety of road users and workers. In the following paragraphs, we will provide a summary of each one.

The partial or total interdiction of vehicle traffic is related to the full or partial interruption of local traffic, increasing the possibility of traffic jams and route changes [4,19,21-33]. Generally, the locations that suffer the most from this impact are those located close to large cities where urbanization is denser and the streets may be narrower [24]. There is also an increase in the local traffic volume due to the transit of heavy equipment and receipt and removal of materials from the construction site [28].

Changes in local pedestrian traffic refer to route changes and lengthening of the route. They occur mainly due to the closing of lanes, blocking sidewalks, and the redirection public transport [4,21-23,28-32]. Sorokin [29] classifies pedestrian and vehicle traffic as extremely important since the most valuable resource for citizens is the time spent commuting. In addition, there is also the discontent caused by the increase in the length of route to be walked. Chatziioannou [23] found that passersby, in general, are willing to walk for a maximum of $10 \mathrm{~min}$ or $750 \mathrm{~m}$ of distance.

The reduction in the usable space used by the population is related to the decrease in areas used for parking and living [19,21,25]. According to Çelik [19], many residents find it challenging to park, even close to their homes. The reduction in parking spaces aggravates this situation.

Infrastructure works can also damage the existing pavement, mainly because of heavy equipment traffic [34], the increased flow of vehicles due to the relocation of traffic, and the removal and reconstruction of the pavement either on the carriageway or the sidewalk $[4,21,22,25,31,35]$.

Concerning the local economy, the impacts caused by road interventions can be reflected in business activities. The interruptions in service and/or limitation of access 
generate social and economic impacts that can be very significant [21,36-38], such as the reduction in productivity and delays at work [25]. Access to the workplace and restocking stocks can be hampered by increased traffic congestion, reduced parking spaces, and the creation of physical barriers [22]. According to these authors, the impacts can be especially severe for companies that depend on people's traffic, such as restaurants, cafes, and gas stations. Another point to be highlighted is that infrastructure implementation/revitalization usually occurs when the economy is heated or can afford to do so [4].

The damage caused to the local economy also reduces tax collection due to the reduction in revenue from local businesses and public parking lots [4,22,25].

Additional expenses with cleaning are associated with the waste produced by construction activities, such as rubble and dust $[4,19,22,25,27,28,39]$. Solid waste and dust must be managed correctly in order not to cause environmental damage, which implies costs $[22,27,28]$. Concerning dust, in addition to affecting air quality, on sunny and dry days heavy dust can be seen, and rainy days result in mud [4]. Such consequences generate the need for additional cleaning [25], which would not exist without intervention, directly affecting the quality of life of the surrounding population [22].

Damage to preexisting networks is addressed in the literature as being related to accidents and scheduled interruptions caused by the implementation of new infrastructure $[4,21,25,31,36-38,40]$. For example, excavation to implement a new gas network can damage an already installed electricity network. Failure in an infrastructure network can generate a ripple effect, meaning that damage to one stretch can affect the adjacent stretch, as well as other networks. In addition to the temporary interruption of service until the network is repaired [4,31], the service interruption cost is passed onto society $[25,36]$.

Noise pollution is associated with the noise increase resulting from the equipment used in the interventions and the rise in traffic due to flow relocation $[4,17,20,22-24,26,28,29,33,37,41]$. Noise pollution can cause psychological and pathological effects and reduce the property's value [42,43]. According to Matthews [22], the increase of $1 \mathrm{dBA}$ in ambient noise generates a decrease of $0.4 \%$ in the house's value. In addition, increased noise can also reduce productivity at local companies [25].

Air pollution is associated with reduced air quality. Economic growth, urbanization, and, consequently, interventions to adapt the infrastructure are linked to increased energy consumption and greenhouse gas emissions [4,21,22,24,26-28,30,33,36,38,39,44]. Currently, equipment that consumes fossil fuels predominates in civil construction [21,22,24,33]. Open-pit surface excavation is common in implementing and maintaining infrastructure networks, which requires machinery for excavation and transport, which normally use combustion engines emissions that heavily pollute the air. In addition, as previously observed, infrastructure works are responsible for the suspension of particles, thus contributing to air pollution [21,27].

Regarding the low energy efficiency of the operation, in combustion engines, a large amount of the produced power is lost in the friction between the countless moving parts and accessory engines, such as alternators and fans. Furthermore, a significant portion of the energy produced is wasted by generating heat exchanged with the environment. The increase in congestion also negatively impacts the operation's energy efficiency, with public transport being an example of high energy consumption $[4,24,38]$.

Changes in the local landscape are associated with changes mainly caused by the construction site implementation, excavations, permanence of equipment, and changes in vegetation cover $[4,19,21,23,29,36,37,39,42]$. For Sorokin [29], the visual environment impacts a person's mental and physiological condition. As for Xue [4], the negative appearance of the city has a negative effect on the city and people's lives.

Damage to the underground ecosystem is related to excavation and contamination due to accidents and leaks [21,25,28,29,31,39,40,45], especially concerning the roots, underground fauna, and groundwater. Matthews [22] advocates using minimally invasive constructive technologies in order refrain from interrupting and disturbing existing biological life. In terms of contamination, Elmasry [25], Patil [28], and Sorokin [29] point 
out that faults can contaminate geological objects and groundwater, as well as the entire underground ecosystem.

Finally, the risks to the safety of road users and workers refer to the risk of pedestrian falls, road accidents, work accidents, and accidents caused by extensive machinery, especially when it comes to open ditches [21-23,28,32,38]. In terms of open-air ditches, Matthews [22] identified that accidents related to this type of construction are $112 \%$ more numerous than other methods. Due to the handling of the pavement due to excavations, sidewalks and roadways present imperfections. Ferreira [35] identified that much of the population is afraid of falling on sidewalks due to these imperfections.

Table 1 summarizes the fourteen impacts of infrastructure work on public roads and the authors who cited them.

Table 1. Selected impacts.

\begin{tabular}{cc}
\hline Impacts & Authors \\
\hline Partial or total interdiction of vehicle traffic & {$[4,19,21-26,28-33]$} \\
\hline Interruptions and changes in local pedestrian traffic & {$[4,21-23,28-32]$} \\
\hline Reduction in public space used by the population & {$[19,21,25]$} \\
\hline Damage to the pavement & {$[4,21,22,25,31,35,39]$} \\
\hline Damage to the local economy & {$[4,21,22,25,36-38]$} \\
\hline Reduction in tax collection & {$[4,17,22,25]$} \\
\hline Additional cleaning expenses & {$[4,19,22,25,28,39]$} \\
\hline Damage to preexisting networks & {$[4,21,25,31,36,38,40]$} \\
\hline Damage to the underground ecosystem & {$[21,25,28,29,31,39,40,45]$} \\
\hline Change in local landscape & {$[4,19,21,23,29,37,39,42]$} \\
\hline Noise pollution & {$[4,20,22-24,26,28,29,33,37,41]$} \\
\hline Atmospheric pollution & {$[4,21,22,24,27,28]$} \\
\hline
\end{tabular}

As will be presented in the next section, this set of impacts served as the basis for the survey questions addressing the importance of each impact.

\section{Materials and Methods}

\subsection{General Approach}

This study had two main objectives: The first was to investigate the main impacts caused by the construction of infrastructure on public roads. The second was to prioritize these impacts from the point of view of the residents of areas affected by these works, the road users, and the Brazilian professionals with experience in the concerned field. We designed an approach in three steps for achieving these objectives: bibliographic research, survey, and data analysis.

\subsection{Bibliographic Research}

We carried out a broad and detailed bibliographic research on the Web of Science, Scopus, Scielo, and on the websites of the main scientific journals. We took into account the recommendations of $[7,8,46]$ and used Preferred Reporting Items for Systematic Reviews and Meta-Analysis (PRISMA) [47].

We used the keyword "urban infrastructure" combined with the keywords "environmental impact," "social impact," and "economic impact" to search for works published from 2014 onwards. The bibliographic research included papers published in the last five years (from 2014) so that the impacts of infrastructure works were more representative of current reality. We also adopted the criterion of only considering English, Portuguese, or Hispanic articles published in journals. 
Then, we excluded the articles that did not provide full text and read titles and abstracts in order to discard works that did not have clear and relevant information on the topic. As a result, we excluded 385 articles. The remaining 156 articles were read in detail, 53 of which were effectively used and served as a basis for identifying impacts. Figure 1 summarizes the bibliographic research by using the PRISMA flowchart.
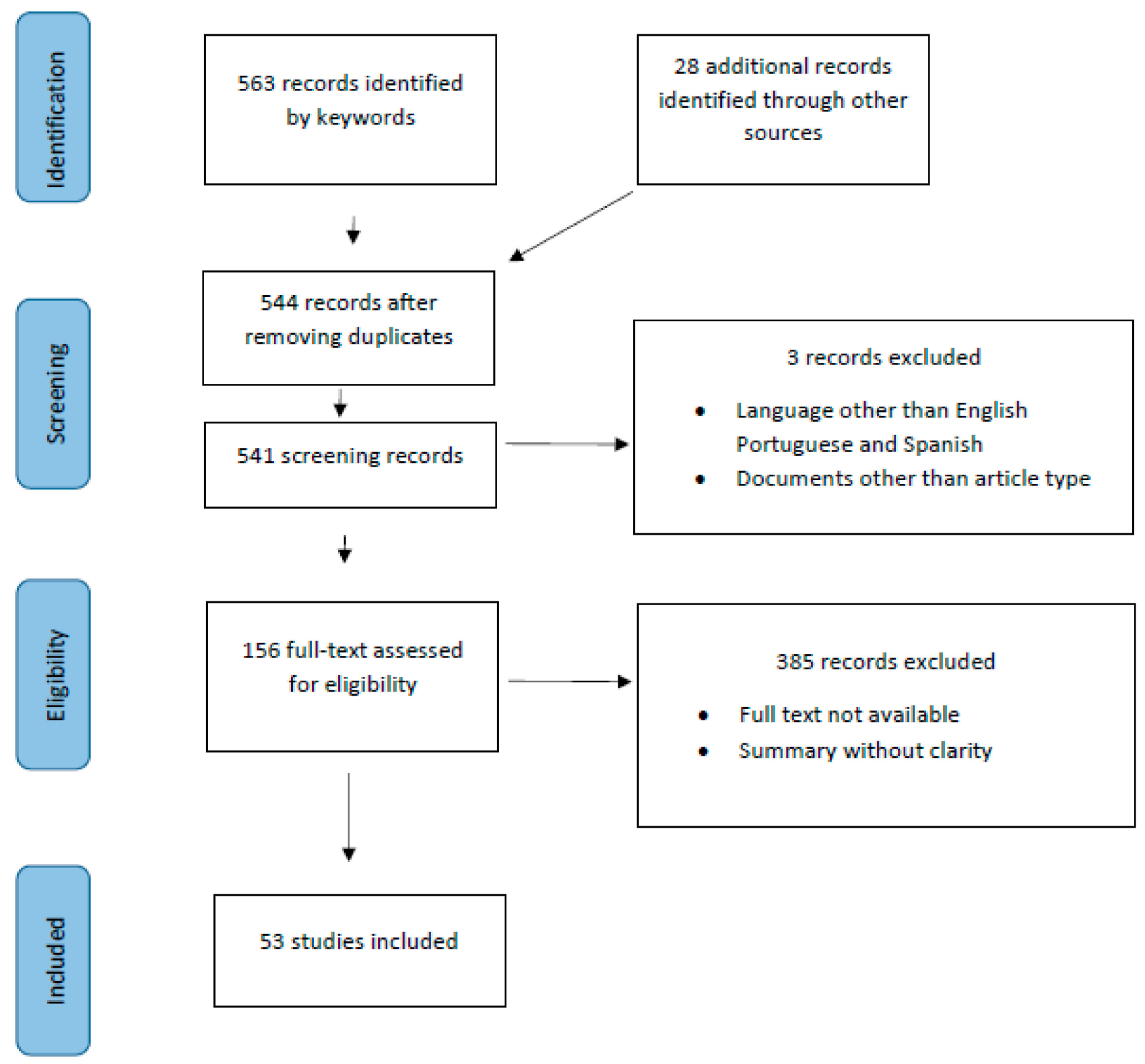

Figure 1. Bibliographic research from the PRISMA flowchart.

\subsection{Survey}

We used a structured questionnaire on an online platform (Google Forms) in order to survey the opinion of residents and users of the adjacent roads to the Rio 2016 Olympic Park, a region directly affected by infrastructure works, and engineers and architects with knowledge on the subject.

The delimited area for data collection was the Olympic Park's surroundings in Barra da Tijuca in the state of Rio de Janeiro, host of the Rio 2016 Olympic Games (Figure 2). This area underwent intense modernization and adaptation of the existing infrastructure [48]. 


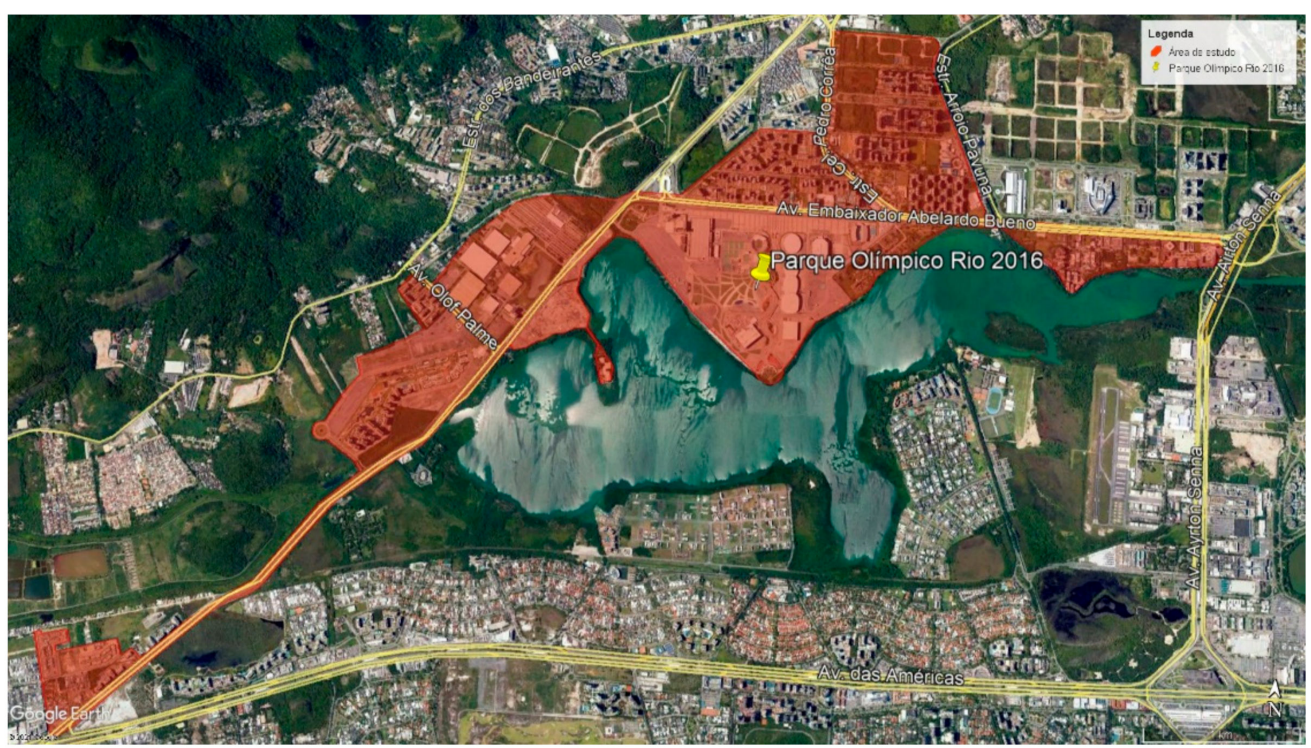

Figure 2. Study area.

The questionnaire was structured into the following four sections: research presentation, demographic data, questions addressing the importance of each impact (Table 1), and finally acknowledgments. Respondents expressed their opinions by using a five-point Likert scale, ranging from minimally important to extremely important. The questions were randomly presented so that there was no bias. The pre-test was carried out to collect opinions on the general design of the questionnaire, clarity, and relevance of the questions and, thus, identify possible inconsistencies or doubts.

We use social networks, WhatsApp, and emails to send out the questionnaire access link to residents and users in the region directly affected by the infrastructure works. We also counted on the support of representatives of condominiums that make up the Rio 2 Residents Association (AMORIO2), the largest association of residents in the region, to send the link. We invited residents of the condominiums surrounding the Olympic Park, members of the region's residents' association, and road users and residents to participate in the survey. Concerning professionals, we used WhatsApp and emails to send the questionnaire access link to engineers and architects who are part of the authors' relationship network. The data survey was carried out from 18 September 2020 to 2 April 2021 and resulted in 103 responses from residents, 63 from users, and 41 from professionals.

\subsection{Data Analysis}

In order to evaluate the questionnaire's reliability and the respondents, we used Cronbach's Alpha for which the value of 0.89 confirmed the reliability of the data. In order to prioritize the impacts, we used the concept of the relative median $[7,8]$, which allows the ranking of impacts in each semantic classification of the Likert scale. For the purposed of illustration, Figure 3 shows that the median of the first line has a value equal to 4 , and the value is very close to 3 . In the second line, with the simple addition of frequency 5 , this same median changes position, occupying more on the right. In both situations, we have medians equal to 4 , but the median is closer to frequency 5 in the second line, which can be interpreted as more important than the previous one. 
Figure 3. Example of median position [7].

The following formula was used to calculate the relative median [7]:

$$
R \mathrm{~m}=\left\{\begin{array}{cc}
1+\frac{\operatorname{Pr}}{\mathrm{j}_{1}} & \text { for } \mathrm{m}=1 \\
\mathrm{~m}+\frac{\operatorname{Pr}-\left(\sum_{i=1}^{\mathrm{m}-1} \mathrm{j}_{\mathrm{i}+1}\right)}{\mathrm{j}_{\mathrm{i}}} & \text { for } 2 \leq \mathrm{m}<\mathrm{N} \mathrm{e} \mathrm{m}=\text { integer } \\
\mathrm{m}+0.5 & \text { for } 1 \leq \mathrm{m}<\mathrm{N} \text { and } \mathrm{m}=\text { fractional number } \\
\mathrm{N} & \text { for } \mathrm{m}=\mathrm{N}
\end{array}\right\}
$$

where $\mathrm{Rm}$ is the relative median, $\mathrm{m}$ is the median, $\mathrm{Pr}$ is the median position, $\mathrm{N}$ is the number of respondents, and $\mathrm{ji}$ is the number of respondents assigned with the semantic classification of " $i$ ".

\section{Results and Discussion}

The main results are the set of identified impacts (Table 1) and the information obtained from the survey, which are presented and discussed below.

Figures 4-6 show the impacts classified by the relative median for the residents, users, and professionals. All impacts were considered important by the specialists (the relative medians were higher than 3.0), corroborating the view of the researchers who publish on the subject.

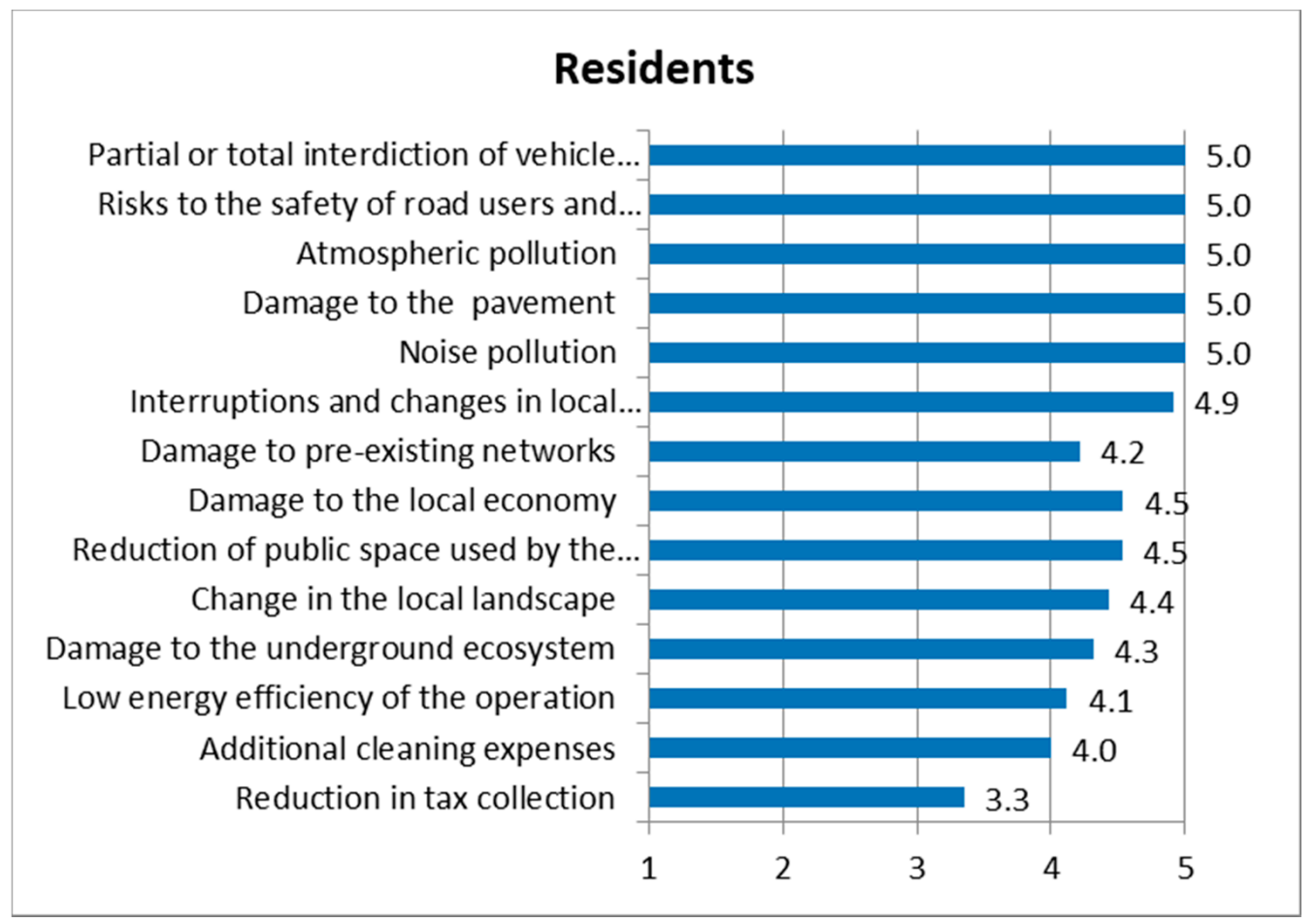

Figure 4. Impacts ranked by the relative median based on the residents. 


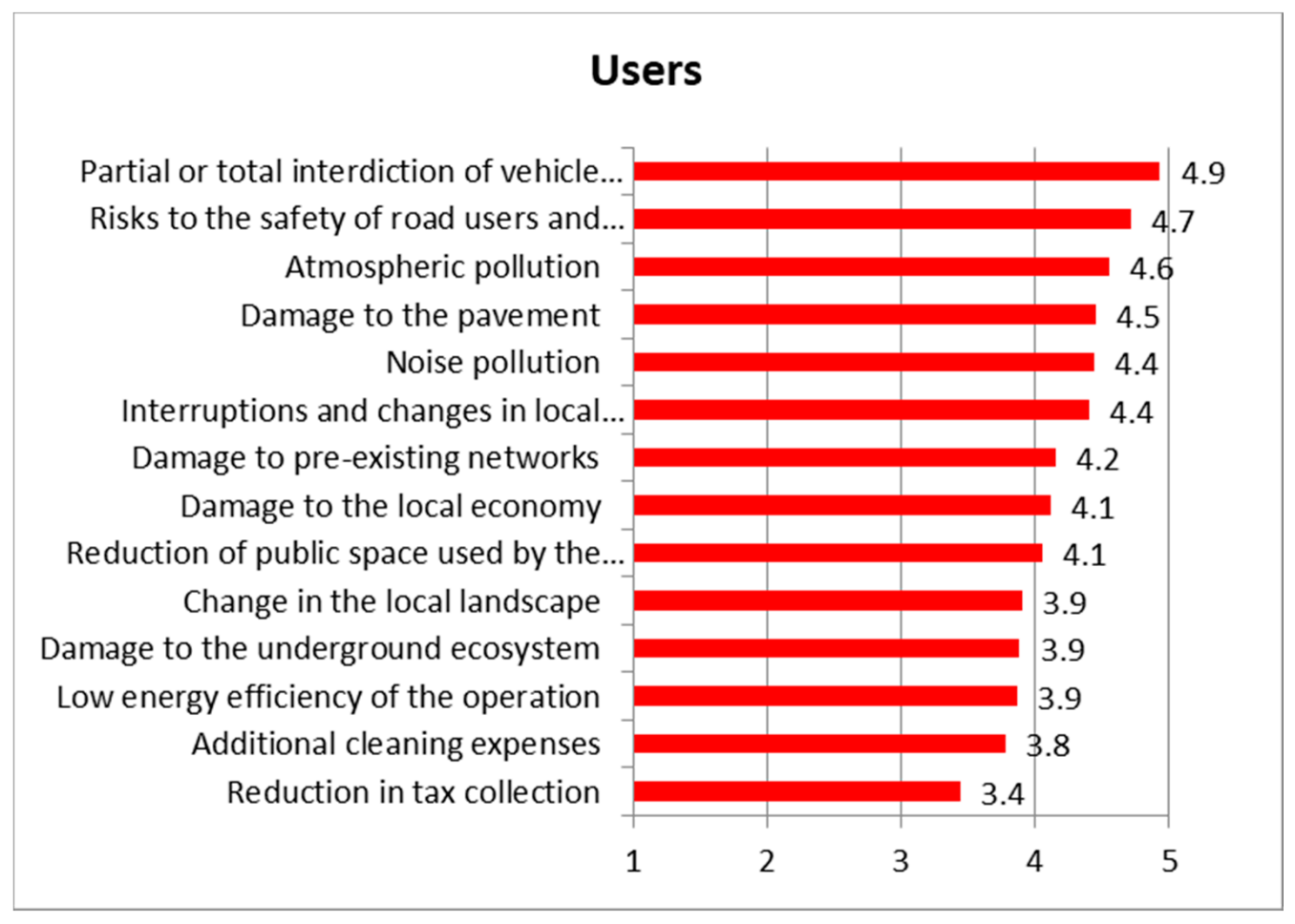

Figure 5. Impacts ranked by the relative median based on the users.

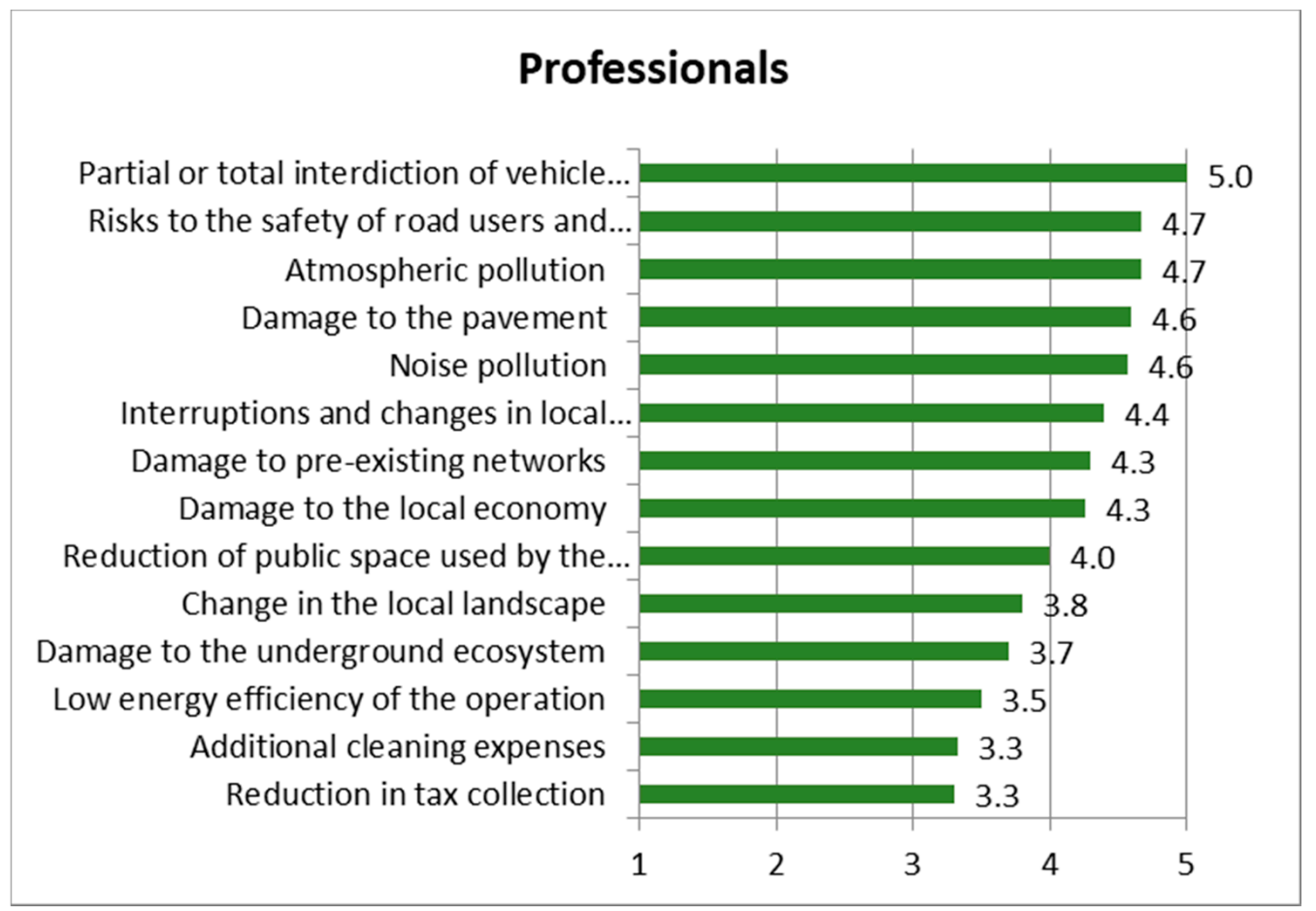

Figure 6. Impacts ranked by the relative median based on the professionals.

Figure 7 shows the impacts' relative behavior for the three groups of respondents. It is possible to note that the magnitude of impacts was greater for residents, followed by professionals and users. 


\section{Impact Behavior}

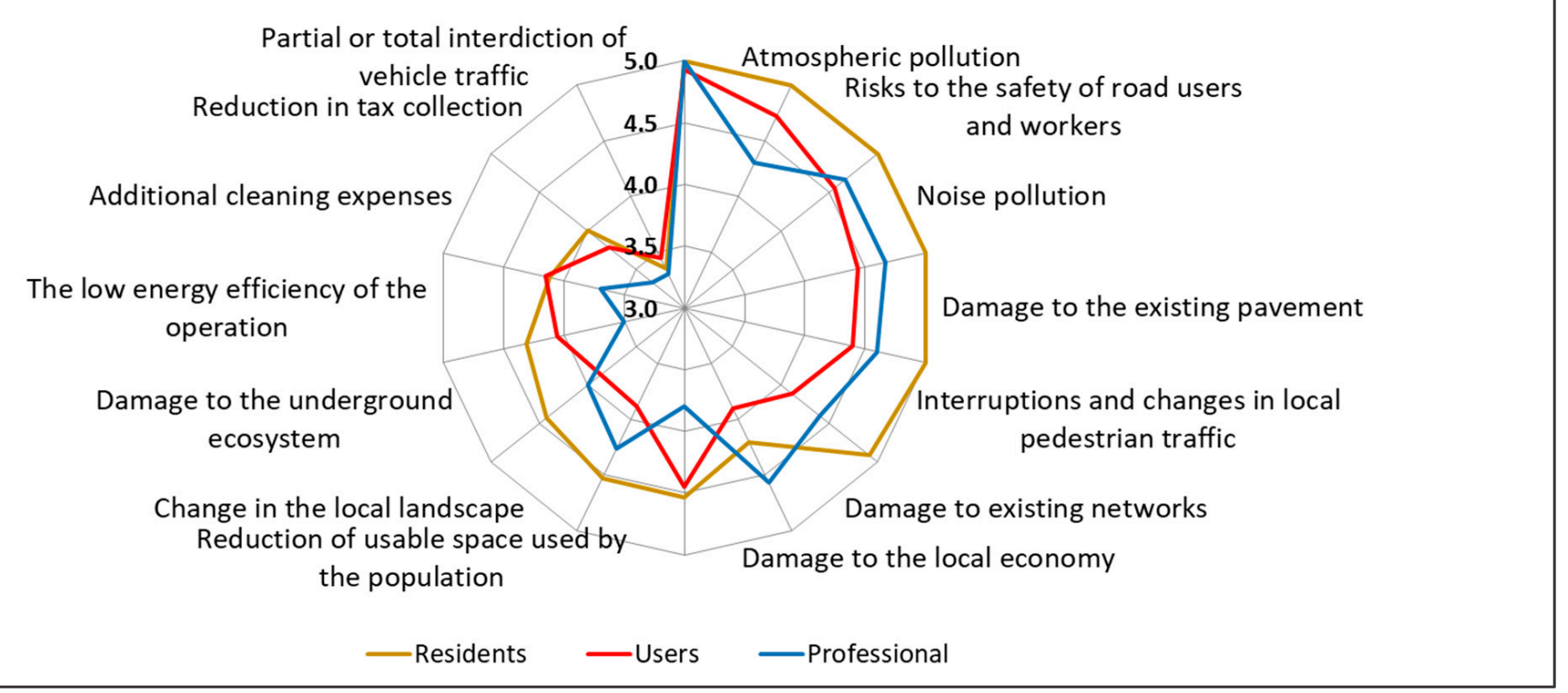

Figure 7. Impacts' relative behavior.

Table 2 shows that seven impacts were rated by the residents, users, and professional as being higher than 4.5 from the relative median: partial or total interdiction of vehicle traffic, risks to the safety of road users and workers, atmospheric pollution, damage to the pavement, noise pollution, interruptions and changes in local pedestrian traffic, and damage to preexisting networks.

Table 2. Main impacts.

\begin{tabular}{cccc}
\hline Impacts & Residents & Users & Professionals \\
\hline Partial or total interdiction of vehicle traffic & 5.0 & 4.9 & 5.0 \\
\hline Atmospheric pollution & 5.0 & 4.7 & \\
\hline Risks to the safety of road users and workers & 5.0 & 4.6 & 4.7 \\
\hline Noise pollution & 5.0 & & 4.7 \\
\hline Damage to the pavement & 5.0 & & 4.6 \\
\hline Interruptions and changes in local pedestrian traffic & 4.9 & \\
\hline Damage to preexisting networks & & & \\
\hline
\end{tabular}

Only two impacts were considered extremely important by the three groups of respondents: partial or total interdiction of vehicle traffic and risks to the safety of road users and workers.

Regarding the impact "partial or total interdiction of vehicle traffic on the residents and users", the results must be analyzed by considering the consequences of the impacts on their daily lives. As they live in the vicinity of the works, residents suffer most from interruptions and alterations in the traffic of vehicles and pedestrians. They interfere with walking, make it difficult for cars to leave garages, and make traffic slower. For road users, what matters most is being able to commute to work, leisure, and residence in the shortest time possible without incurring additional costs.

In the Xue [4] study, this impact was also considered the most important, mainly due to traffic problems and the effect on daily commuting costs. He also concluded that this impact is more significant for people who do not own a car. From the point of view of the additional costs caused by the partial or total interdiction of vehicle traffic, Mathews et al. [22] highlight 
the costs of travel delays, especially in dense urban areas, and the operational costs of vehicles. Celik et al. [19] highlighted the costs caused by deceleration, reduced speed, and acceleration and delay in the vehicle queue, in addition to the increase in vehicle operating costs due to the reduction in available lanes. Elmasry et al. [25] highlighted the increase in vehicle operating costs due to the use of detours.

As for the risks to the safety of road users and workers, the partial closure of the roads, the location, size, access to the construction site, open ditches and imperfect roads, sidewalks and cycle paths, and intensive use of equipment, especially extensive machinery, are characteristics of these works that may have influenced the respondents' judgment and are also reported in the literature. They can cause pedestrian falls and work and traffic accidents. According to Gomes [42], traffic accidents have short and long-term effects, such as deaths and serious injuries and psychological, financial, and daily life damage. According to Mathews et al. [22], continuous open trenches pose a higher risk to workers and pedestrians compared with the pits/shafts employed by trenchless construction methods.

Noise pollution and atmospheric pollution were rated by residents as priority impacts. Users only rated atmospheric pollution as a priority impact, and professionals only rated noise pollution as a priority impact. Infrastructure works usually make intensive use of equipment that is generally very noisy and pollutes the environment. Furthermore, it is necessary to relocate traffic to streets with little traffic in many cases, significantly increasing noise and dust on these roads. In addition, dust and noise also hinder the productive activities of local companies. This makes the population and businesses close to the location more impacted by noise and air pollution. According to Xue et al. [4], construction site noise, mainly caused by mechanical activities in the construction process, influences the frequency of listening, distraction, and various behaviors of local residents, animals, and birds. Mathews et al. [22] points out that noise from changing traffic conditions can also affect social, behavioral, mental, and physical health. They also highlight that dust pollution produced by open excavations increases cleaning needs and reduces the quality of life for people living near the construction zone. Regarding users, we interpret that the fact that they are normally subjected to noise for a short time meant that they did not assess this impact as extremely important. However, concerning air pollution, we believe that the longer commuting time caused by traffic jams, associated with the fact that the main Brazilian means of transport use highly polluting fossil fuels, made this impact extremely important by users.

Pavement damage was rated by residents and professionals as a priority impact. Heavy machinery traffic causes damage and wear to the road surface [21]. Open excavations cause accelerated pavement degradation by deforming it and causing cracks in the asphalt at the edges of the trench, reducing its useful life by up to $30 \%$ [22]. Changing traffic to secondary roads also promotes early pavement damage. They are generally not designed for the flow of relocated vehicles and sized for heavy vehicle traffic, mainly impacting residents. It is worth noting that overloading or overloading significantly impacts the achievement of the road project's lifetime [49]. Upon completion of the work, the final results of the paving service and the restoration of sidewalks and curbs are also important factors in the perception and association of damage relative to infrastructure works. In this case, the need for early maintenance, in addition to increasing costs, can again interfere with the road functioning [21], increasing the feeling of prejudice for the citizen. In addition, Ferreira et al. [35] highlights that defects in the sidewalks cause concern in the elderly and people with special needs in terms of leaving the house, which is an important barrier to social participation. This situation has been experienced frequently by the citizens of most Brazilian cities and demands professionals' planning capacity and specific technical knowledge.

Interruptions and changes in local pedestrian traffic were rated by residents as a priority impact. Pedestrians and cyclists can be forced to swerve due to the rerouting of public transport services and blocked sidewalks and cycle paths [22]. They may also require temporary relocation of parking spaces [50] which can obstruct pedestrians' paths 
and particularly harm people with special needs, such as wheelchair users and those who travel with a pram. Additionally, alternative routes can present specific vulnerabilities for pedestrians and cyclists, such as uneven, slippery, or excessively rough surfaces. They can also cause dissatisfaction due to the increase in the length of the journey to be covered [23].

Damage to preexisting networks was rated by residents and professionals as a priority impact. Kwast-kotlarek et al. [21] highlight that in works using traditional methods, excavation work must be carried out with great care due to the risk of causing damage to the existing underground infrastructure, which usually delays the schedule, increasing the period for exposure to the impacts of the work for residents. In addition, the interruption in one network can cause a ripple effect in other networks, which impacts the community and the economy in general [36]. The fact that different companies manage networks usually makes repairs time-consuming.

The evaluation carried out by the professionals was closer to that carried out by the residents. In addition to the partial or total interdiction impacts of vehicle traffic, risks to the safety of road users and workers and noise pollution were also rated as more important by residents. Professionals probably realize that damage to preexisting networks can generate a cascade effect, impairing the supply from other services.

It is important to note that, in the residents' perception, five impacts had a maximum relative median (5.0): partial or total interdiction of vehicle traffic, risks to the safety of road users and workers, atmospheric pollution, damage to the pavement, and noise pollution.

The impacts with the lowest degree of importance for the three groups were reduced tax collection and additional cleaning expenses, with the relative median varying from 3.3 to 4.0 .

In order to reduce the impacts addressed in this study, public policies regarding the regularization and authorization of these interventions are fundamental in several aspects, such as those referring to the times for interventions and constructive methods. As for the schedule of activities, it is important to observe the environment surrounding the intervention. Residential areas make night work unfeasible or challenging due to impacts such as noise pollution.

Although there are already less invasive solutions that reduce the impacts identified in this study, they are still little used in most cities in underdeveloped and developing countries. We highlight three solutions: trenchless technologies, lane rental, and urban utility tunnels.

Less invasive methods such as trenchless technologies and micro trenchers minimize disruption to traffic when crossing a road through its basement. Trenchless technologies, in addition to producing less dust, usually reduce gas emissions. Kwast-Kotlarek et al. [21] found that trenchless technologies can reduce gas emission to the atmosphere by up to $80 \%$ compared to the traditional open-pit excavation method. Although micro trenchers enter the bearing races, they cause less impact because they use high-speed equipment such as micro trenchers.

Lane rental is an instrument used by the local authority to minimize the impact of the works on the population [51]. By using lane rental, the contractor is charged a lane rental for the period of time his work occupies the public road; that is, the lane must be rented to be closed. This strategy creates a monetary incentive for the contractor to seek more innovative and efficient solutions to minimize the duration of the lane closure.

Urban utility tunnels are tunnels in the city's underground space, with special maintenance shafts and monitoring systems, which incorporate energy, sanitation, telecommunications, gas, and other municipal cables and pipelines [52]. These tunnels reduce the need for road works by enabling the occurrence of new service and maintenance connections with minimal or no excavation, in addition to helping in minimizing underground congestion [53].

\section{Conclusions}

The infrastructure implementation and renovation in cities require works on public roads that impact the daily lives of road users and local population and commerce. Al- 
though the study of the impacts of infrastructure works in the researched literature has received various approaches, there is still a shortage of studies that identify the impacts of the implementation of infrastructure on public roads and the importance of each one.

Based on extensive and detailed bibliographic research, we identify 14 impacts caused by infrastructure works on public roads, which were also considered important by residents of areas impacted by these works, road users, and Brazilian professionals with experience in the field. Seven of these drivers were rated as the most important by the survey respondents.

The survey results confirmed the authors' view of the consulted articles since all impacts were evaluated as important by the three groups of respondents. However, it is important to note that opinion polls of all research based on experts' judgment have some degree of subjectivity resulting from the evaluator's interpretation of what is being evaluated.

Of the seven impacts considered most important, two relate to pollution and are frequently associated with civil construction works (atmospheric pollution and noise pollution), two relate to interruptions or changes in flow (partial or total interdiction of vehicle traffic and interruptions and changes in local pedestrian traffic), two relate to damage (damage to the pavement and damage to preexisting networks), and one refers to security (risks to the safety of road users and workers). Reduced tax collection and additional cleaning expenses were the least important impacts by the three groups of respondents.

It is most recommended that all impacts addressed in this study be considered by companies, public bodies, managers, professionals, and legislators. However, the set of seven impacts assessed as the most important should be prioritized in a scarcity of resources.

This research has the typical limitation of studies that rely on a literature review to support the results. Although we have carried out extensive and detailed bibliographic research, there is always the possibility that an important article was not included. A second limitation is that the prioritization of impacts was based only on assessments by Brazilian respondents, which the Brazilian reality may have influenced. Thus, generalizations must consider local realities. However, the realities experienced in Brazilian cities are present in most underdeveloped and developing countries.

Author Contributions: Conceptualization, survey, data curation, methodology, writing-original draft, formal analysis, and writing-review and editing, E.A.N.e.S. and C.A.P.S.; visualization, writing-review and editing, C.T.d.S.D., C.K.C., A.N.H. and A.W.A.H.; supervision, C.A.P.S. All authors have read and agreed to the published version of the manuscript.

Funding: This research received no external funding.

Institutional Review Board Statement: Not applicable.

Informed Consent Statement: Not applicable.

Data Availability Statement: Not applicable.

Acknowledgments: The authors would like to thank Fluminense Federal University, Brazil, for supporting the research reported in this paper and all the respondents who answered the survey. The authors also express their gratitude to the editor and anonymous reviewers for their comments and suggestions.

Conflicts of Interest: The authors declare no conflict of interest.

\section{References}

1. Gardner, D.; Lark, R.; Jefferson, T.; Davies, R. A survey on problems encountered in current concrete construction and the potential benefits of self-healing cementitious materials. Case Stud. Constr. Mater. 2018, 8, 238-247. [CrossRef]

2. He, L.; Ma, G.; Hu, Q.; Cai, Q.; Bai, Y.; Tang, S.; Tan, J. A Novel Method for Risk Assessment of Cable Fires in Utility Tunnel. Math. Probl. Eng. 2019, 2019, 2563012. [CrossRef]

3. Mteki, N.; Murayama, T.; Nishikizawa, S. Social impacts induced by a development project in Tanzania: A case of airport expansion. Impact Assess. Proj. Apprais. 2017, 35, 272-283. [CrossRef]

4. Xue, X.; Zhang, R.; Zhang, X.; Yang, R.J.; Li, H. Environmental and social challenges for urban subway construction: An empirical study in China. Int. J. Proj. Manag. 2015, 33, 576-588. [CrossRef]

5. Zhang, R.; Shi, G.; Wang, Y.; Zhao, S.; Ahmad, S.; Zhang, X.; Deng, Q. Social impact assessment of investment activities in the China-Pakistan economic corridor. Impact Assess. Proj. Apprais. 2018, 36, 331-347. [CrossRef] 
6. Barcellos, P.D.C.L.; Da Costa, M.S.; Cataldi, M.; Soares, C.A.P. Management of non-structural measures in the prevention of flash floods: A case study in the city of Duque de Caxias, state of Rio de Janeiro, Brazil. Nat. Hazards 2017, 89, 313-330. [CrossRef]

7. De Alcantara, R.G.; de Alcantara, M.C.P.G.; Chinelli, C.K.; Dias, F.C.; Mariano, R.L.V.; Longo, O.C.; Soares, C.A.P. The Main Drivers to Face the Challenges of Increasing the Intelligence of Sanitary Sewage Systems in Brazilian Cities. Water 2020, $12,3478$. [CrossRef]

8. Lima, E.G.; Chinelli, C.K.; Guedes, A.L.A.; Vazquez, E.G.; Hammad, A.W.A.; Haddad, A.N.; Soares, C.A.P. Smart and Sustainable Cities: The Main Guidelines of City Statute for Increasing the Intelligence of Brazilian Cities. Sustainability 2020, $12,1025$. [CrossRef]

9. Maldonado Silveira Alonso Munhoz, P.A.; da Costa Dias, F.; Kowal Chinelli, C.; Azevedo Guedes, A.L.; Neves dos Santos, J.A.; da Silveira e Silva, W.; Pereira Soares, C.A. Smart Mobility: The Main Drivers for Increasing the Intelligence of Urban Mobility. Sustainability 2020, 12, 10675. [CrossRef]

10. Talari, S.; Shafie-khah, M.; Siano, P.; Loia, V.; Tommasetti, A.; Catalão, J.P.S. A Review of Smart Cities Based on the Internet of Things Concept. Energies 2017, 10, 421. [CrossRef]

11. Al-Bayati, A.J.; Panzer, L. Reducing Damage to Underground Utilities: Lessons Learned from Damage Data and Excavators in North Carolina. J. Constr. Eng. Manag. 2019, 145, 04019078. [CrossRef]

12. Anspach, J.H. Standard Guideline for the Collection and Depiction of Existing Subsurface Utility Data; ASCE: Reston, VA, USA, $2002 ;$ p. 1.

13. Ariaratnam, S.T.; Piratla, K.; Cohen, A.; Olson, M. Quantification of Sustainability Index for Underground Utility Infrastructure Projects. J. Constr. Eng. Manag. 2013, 139, A4013002. [CrossRef]

14. Hammad, A.W.A.; Akbarnezhad, A.; Rey, D. A multi-objective mixed integer nonlinear programming model for construction site layout planning to minimise noise pollution and transport costs. Autom. Constr. 2016, 61, 73-85. [CrossRef]

15. Xiao, J.; Li, X.; Zhang, Z. DALY-Based Health Risk Assessment of Construction Noise in Beijing, China. Int. J. Environ. Res. Public Health 2016, 13, 1045. [CrossRef]

16. Kabeer, N.; Sulaiman, M. Assessing the Impact of Social Mobilization: Nijera Kori and the Construction of Collective Capabilities in Rural Bangladesh. J. Human Dev. Capab. 2015, 16, 47-68. [CrossRef]

17. Xiahou, X.; Tang, Y.; Yuan, J.; Chang, T.; Liu, P.; Li, Q. Evaluating Social Performance of Construction Projects: An Empirical Study. Sustainability 2018, 10, 2329. [CrossRef]

18. Ferrarez, R.P.F.; Vargas, R.V.; Alvarenga, J.C.; Chinelli, C.K.; de Almeida Costa, M.; de Oliveira, B.L.; Haddad, A.N.; Soares, C.A.P. Sustainability Indicators to Assess Infrastructure Projects: Sector Disclosure to Interlock with the Global Reporting Initiative. Eng. J. 2020, 24, 43-61. [CrossRef]

19. Çelik, T.; Arayici, Y.; Budayan, C. Assessing the social cost of housing projects on the built environment: Analysis and monetization of the adverse impacts incurred on the neighbouring communities. Environ. Impact Assess. Rev. 2019, 77, 1-10. [CrossRef]

20. Dong, Y.H.; Ng, S.T. A social life cycle assessment model for building construction in Hong Kong. Int. J. Life Cycle Assess. 2015, 20, 1166-1180. [CrossRef]

21. Kwast-Kotlarek, U.; Hełdak, M. Evaluation of the Construction and Investment Process of a High-Pressure Gas Pipeline with Use of the Trenchless Method and Open Excavation Method. Analytic Hierarchy Process (AHP). Sustainability 2019, 11, 2438. [CrossRef]

22. Matthews, J.C.; Allouche, E.N.; Sterling, R.L. Social cost impact assessment of pipeline infrastructure projects. Environ. Impact Assess. Rev. 2015, 50, 196-202. [CrossRef]

23. Chatziioannou, I.; Alvarez-Icaza, L. Evaluation of the urban transportation infrastructure and its urban surroundings in the Iztapalapa County: A geotechnology approach about its management. Cogent Eng. 2017, 4, 1330854. [CrossRef]

24. De Marco, A.; Mangano, G.; Zenezini, G. Classification and benchmark of City Logistics measures: An empirical analysis. Int. J. Logist. Res. Appl. 2018, 21, 1-19. [CrossRef]

25. Elmasry, M.; Hawari, A.; Zayed, T. Cost benefit analysis for failure of sewer pipelines. MATEC Web Conf. 2017, 120. [CrossRef]

26. Janné, M.; Fredriksson, A. Construction logistics governing guidelines in urban development projects. Constr. Innov. 2019, 19, 89-109. [CrossRef]

27. Molina, L.; Velasco, E.; Retama, A.; Zavala, M. Experience from Integrated Air Quality Management in the Mexico City Metropolitan Area and Singapore. Atmosphere 2019, 10, 512. [CrossRef]

28. Patil, N.A.; Tharun, D.; Laishram, B. Infrastructure development through PPPs in India: Criteria for sustainability assessment. J. Environ. Plann. Manag. 2016, 59, 708-729. [CrossRef]

29. Sorokin, A.; Larionova, Y.; Tolstykh, E. Constructional sustainability impact on the comfort of living environment. MATEC Web Conf. 2018, 193, 04026. [CrossRef]

30. Tao, Z. Research on the Degree of Coupling between the Urban Public Infrastructure System and the Urban Economic, Social, and Environmental System: A Case Study in Beijing, China. Math. Probl. Eng. 2019, 2019, 8206902. [CrossRef]

31. Tscheikner-Gratl, F.; Egger, P.; Rauch, W.; Kleidorfer, M. Comparison of Multi-Criteria Decision Support Methods for Integrated Rehabilitation Prioritization. Water 2017, 9, 68. [CrossRef]

32. Yuan, J.-F.; Skibniewski, M.J.; Li, Q.; Shan, J. The Driving Factors of China's Public-Private Partnership Projects in Metropolitian Transportation Systems: Public Sector's Viewpoint. J. Civil Eng. Manag. 2010, 16, 5-18. [CrossRef]

33. Li, S.; Wei, Z. A hybrid approach based on the analytic hierarchy process and 2-tuple hybrid ordered weighted averaging for location selection of distribution centers.(Research Article). PLoS ONE 2018, 13, e0206966. [CrossRef] 
34. Lopes, A.C. Identificação e categorização de riscos empresariais: Um estudo exploratório com fabricantes de cervejas artesanais do estado do Rio de Janeiro. MESC 2019. [CrossRef]

35. Ferreira, F.R.; César, C.C.; de Andrade, F.B.; de Souza, P.R.B.; Lima-Costa, M.F.; Proietti, F.A. Aspects of social participation and neighborhood perception: ELSI-Brazil. Rev. Saúde Pública 2018, 52, 18s. [CrossRef] [PubMed]

36. Hasan, S.; Foliente, G. Modeling infrastructure system interdependencies and socioeconomic impacts of failure in extreme events: Emerging R\&D challenges. Nat. Hazards 2015, 78, 2143-2168. [CrossRef]

37. Mottee, L.K.; Howitt, R. Follow-up and social impact assessment (SIA) in urban transport-infrastructure projects: Insights from the parramatta rail link. Aust. Plann. 2018, 55, 46-56. [CrossRef]

38. Zhou, J.; Liu, Y. The method and index of sustainability assessment of infrastructure projects based on system dynamics in China. J. Ind. Eng. Manag. 2015, 8, 1002-1019. [CrossRef]

39. De Magalhães, R.F.; Danilevicz, Â.D.M.F.; Saurin, T.A. Reducing construction waste: A study of urban infrastructure projects. Waste Manag. 2017, 67, 265-277. [CrossRef]

40. Guo-Fu, W.; Shen, J.; Lin-Hai, L.; Li, G.; Arulrajah, A. Evaluation of Environmental Risk Due to Metro System Construction in Jinan, China. Int. J. Environ. Res. Public Health 2017, 14, 1114. [CrossRef]

41. Momtaz, S.; Kabir, S.Z. Evaluating Environmental and Social Impact Assessment in Developing Countries; Elsevier: Hoboken, NJ, USA, 2013.

42. Gomes, J.A.P.; Alcoforado, L.F.; Guedes, A.L.A.; Soares, C.A.P.; Longo, O.C. Perception of the Impacts of Urban Mobility Interventions in the Niterói Oceanic Region, Brazil. Sustainability 2020, 12, 6052. [CrossRef]

43. Tandel, B.N.; Ruparel, P.; Macwan, J.M. Importance of urban traffic noise pollution in sustainable transportation planning: A review. In Proceedings of the International Journal of Emerging Technologies and applications in Engineering, Technology and Sciences (IJ-ETA-ETS), Gandhinagar, India, 1 July 2011.

44. Colenbrander, S.; Gouldson, A.; Roy, J.; Kerr, N.; Sarkar, S.; Hall, S.; Sudmant, A.; Ghatak, A.; Chakravarty, D.; Ganguly, D.; et al. Can low-carbon urban development be pro-poor? The case of Kolkata, India. Environ. Urban. 2017, 29, 139-158. [CrossRef]

45. Kalkowski, M.; Muggleton, J.; Rustighi, E. Tree root detection from ground surface vibration measurements. MATEC Web Conf. 2018, 148, 1500. [CrossRef]

46. Froufe, M.M.; Chinelli, C.K.; Guedes, A.L.A.; Haddad, A.N.; Hammad, A.W.A.; Soares, C.A.P. Smart Buildings: Systems and Drivers. Buildings 2020, 10, 153. [CrossRef]

47. Moher, D.; Liberati, A.; Tetzlaff, J.; Altman, D.G. Preferred reporting items for systematic reviews and meta-analyses: The PRISMA statement. Int. J. Surg. 2010, 8, 336-341. [CrossRef] [PubMed]

48. Amaral, S.C.F.; Silva, D.S.; Santos, M.I.D.; Vargas, G.R. A sociedade civil e os conflitos na construção dos megaeventos esportivos no Brasil. Soc. E Estado 2014, 29, 637-660. [CrossRef]

49. Awaludin, A.; Hatmoko, J.U.D.; Setiadji, B.H.; Wibowo, M.A.; Matsumoto, T.; Pessiki, S.; Jonkers, H.; Siswosukarto, S.; Fajar Setiawan, A.; Nur Rahma Putri, K. Investigating causal factors of road damage: A case study. MATEC Web Conf. 2019, $258,02007$. [CrossRef]

50. Government, W. Addressing the Needs of Pedestrians and Cyclists When Carrying Out Street Works and Maintenance Activities. Available online: https: / / gov.wales/11420-supplementary-guidance-safety-street-works-and-road-works-code-practice-2013 (accessed on 20 June 2019).

51. Williams, J. On the right road with lane rental? Traffic Eng. Control 2016, 94.

52. Wang, T.; Tan, L.; Xie, S.; Ma, B. Development and applications of common utility tunnels in China. Tunn. Undergr. Space Technol. 2018, 76, 92-106. [CrossRef]

53. Canto-Perello, J.; Curiel-Esparza, J. Assessing governance issues of urban utility tunnels. Tunn. Undergr. Space Technol. 2013, 33, 82-87. [CrossRef] 